\title{
Ocular Trauma: Trends and Considerations for Resident Education
}

\author{
Stephen C. Dryden, MD ${ }^{1} \quad$ Jason D. Jensen, $\mathrm{MD}^{1} \quad$ James C. Fleming, MD FACS ${ }^{1}$ Brian T. Fowler, MD \\ ${ }^{1}$ Department of Ophthalmology, Hamilton Eye Institute, University of \\ Tennessee Health Science Center, Memphis, Tennessee \\ J Acad Ophthalmol 2020;12:e46-e51. \\ Address for correspondence Stephen C. Dryden, MD, Department of \\ Ophthalmology, Hamilton Eye Institute, University of Tennessee \\ Health Science Center, 930 Madison Avenue, Suite 470, Memphis, \\ TN 38163 (e-mail: sdryden1@uthsc.edu).
}

\begin{abstract}
Objective Ocular trauma is a mendable cause of morbidity and preventable blindness. Our goal is to confirm the relationship between ocular trauma and seasonality, to establish an association between ocular trauma and temperature, and to discuss implications on resident education.

Methods Consults for the University of Tennessee Health Science Center Hamilton Eye Institute Ophthalmology residency (Memphis, TN) were recorded in the New Innovations database from 2006 to 2016 and analyzed retrospectively. International Classification of Diseases-9 diagnosis codes were used to identify all cases of ocular trauma. Temperature data were obtained from the National Oceanic and Atmospheric Association. The main outcome measures were the monthly, seasonal, annual, and temperature trends in ocular trauma in an emergency department setting, necessitating an ophthalmology consultation.

Results A total of 8,400 patients were screened by ophthalmology residents in Memphis, TN from 2006 to 2016, 3,540 carried a diagnosis of ocular trauma, out of which 2,290 were male $(64.7 \%$ ) with a mean age of 34.6 years and 1,250 were female (35.3\%) with a mean age of 34.9 years. The most common diagnoses were orbital fracture (36.6\%), eyelid laceration (20.2\%), and nonpenetrating corneal/conjunctival injury (13.6\%). Peak months were July (37.3 cases/year) and September (36.6 cases/year) with trauma more likely to occur in nonwinter months $(p=0.0069)$. Trauma was more likely to occur in the summer/fall seasons $(p=0.0014)$ corresponding to mean temperatures 82.8 and $64.6^{\circ} \mathrm{F}$, respectively.

Conclusion Ocular trauma exhibits an annual and temperature cycle, peaking in the

\section{Keywords}

- ocular trauma

- resident education

- seasonality summer and fall months, and coinciding with the beginning of the academic year. Special attention should be taken in July to prepare residents for the proper management of ocular trauma to prevent blindness as traumatic cases are more likely to require surgical intervention.
\end{abstract}

Ocular trauma is a mendable cause of ophthalmologic morbidity and preventable blindness with an estimated annual charge of $\$ 2$ billion for eye-related emergency department (ED) visits per year in the United States. ${ }^{1}$ Of 12 million ED visits for eye-related reasons from 2006 to
$2011,36.3 \%$ were injuries as a result of trauma. ${ }^{1}$ There is an estimated 55 million eye injuries causing restriction of activities more than 1 day per year worldwide leaving 1.6 million people bilaterally blind, 2.3 million people bilaterally visually impaired, and 19 million people received

August 30, 2019

accepted

March 1, 2020
DOI https://doi.org/

$10.1055 / \mathrm{s}-0040-1709177$ ISSN 2475-4757.
Copyright $\odot 2020$ by Thieme Medical

Publishers, Inc., 333 Seventh Avenue, New York, NY 10001, USA Tel: +1(212) 760-0888
License terms

()ㅇ (1) $\Theta \circledast$ 
unilaterally visually impaired. ${ }^{2}$ The most common cases of ocular trauma reported include corneal abrasions, ocular foreign body, direct trauma, eyelid laceration, and orbital fractures. ${ }^{3}$ The most common mechanisms of eye injury in decreasing incidence are sports injury, falls, fire, chemical exposure, and motor vehicle accident (MVA). ${ }^{4}$ As demonstrated in pediatric populations and reported by Ramirez et al, the volume of ED visits for eye-related complaints increases in the spring and summer months. ${ }^{5-7}$ Trauma has an increased incidence in the spring and summer months, coinciding with the beginning of the academic year. ${ }^{8}$ In the field of ophthalmology where there is limited formal training in medical school and internship, lack of recognition of examination findings in cases of ocular trauma can have devastating consequences. While previous studies have shown that temperature and daylight factors showed correlation with aggressive behaviors, all-cause trauma, and violent crime, no studies could establish a relationship between temperature and ocular trauma. ${ }^{8-10}$ If ocular trauma is more likely to happen in warmer months at the beginning of the academic year, additional training and supervision for novice residents and dedicated rotations during integrated internships might be beneficial. Our goal is to confirm the relationship between ocular trauma and seasonality, to establish an association between ocular trauma and temperature, and to discuss implications on resident education.

\section{Methods}

Institutional Review Board approval from the University of Tennessee Health Science Center was obtained. This study was Health Insurance Portability and Accountability Act compliant and adhered to the tenets of the Declaration of Helsinki. All hospital-based consults from an Accreditation Council for Graduate Medical Education ophthalmology residency program in Memphis, TN, over a 10-year period from July 1, 2006, to June 30, 2016, were reviewed retrospectively. All consults discussed with either a senior resident or attended to confirm the diagnosis and were logged in the New Innovations database. Diagnoses that were not a result of trauma were excluded. Remaining diagnoses were then grouped by type of injury. The hospitals covered included all major hospitals in the Memphis metropolitan area: regional adult and pediatric level 1 trauma centers, multiple level 2 trauma centers, and a VA Medical Center (VAMC). A single-factor analysis of variance (ANOVA) was performed with respect to month over the 2006 to 2016 period. A second single-factor ANOVA was performed with respect to season over the 2006 to 2016 period. A two-sample $t$-test was performed between the spring/summer and fall/winter seasons and winter/spring and summer/fall seasons over the 2006 to 2016 period. Summer was defined as June, July, and August. Fall was defined as September, October, and November. Winter was defined as December, January, and February. Spring was defined as March, April, and May. Average monthly temperature was calculated using data from the National Oceanic and Atmospheric Administration. ${ }^{11}$ Results were deemed statistically significant with a $p$-value $<0.05$.
Table 1 Demographics

\begin{tabular}{|c|c|c|}
\hline \multirow[t]{2}{*}{ Total patients seen } & \multicolumn{2}{|l|}{8,400} \\
\hline & $M$ & $\mathrm{~F}$ \\
\hline & 5,331 & 3,069 \\
\hline \multirow[t]{3}{*}{ Trauma patients } & \multicolumn{2}{|l|}{3,540} \\
\hline & M & $\mathrm{F}$ \\
\hline & 2,290 & 1,250 \\
\hline \multirow[t]{3}{*}{ Age (y) } & \multicolumn{2}{|l|}{34.9} \\
\hline & M & $\mathrm{F}$ \\
\hline & 34.6 & 35.3 \\
\hline Facility & \multicolumn{2}{|c|}{ Patients } \\
\hline Level 1 adult & \multicolumn{2}{|c|}{1,782} \\
\hline Level 1 pediatric & \multicolumn{2}{|l|}{1,016} \\
\hline Level 2 combined & \multicolumn{2}{|l|}{643} \\
\hline VA Medical Center & \multicolumn{2}{|l|}{99} \\
\hline
\end{tabular}

\section{Results}

A total of 8,400 patients over 10 years were evaluated (3,069 females and 5,331 males) of which 3,540 were identified as cases of ocular trauma ( - Table $\mathbf{1}$ ). Ages ranged from 3 weeks old to 99 years old. Of the 3,540 cases, 2,290 were male (64.7\%) with a mean age of 34.6 years, while 1,250 were female $(35.3 \%$ ) with a mean age of 34.9 years ( - Table $\mathbf{1}$ ). Of the 3,540 patients, 535 had multiple traumatic diagnoses bringing the total number of diagnoses to 4,075 (-Table 1). Of the 3,540 patients, $1,782(50.3 \%)$ were treated at level 1 adult trauma center, 1,016 (28.7\%) were treated at level 1 pediatric trauma center, $643(18.2 \%)$ were treated at level 2 trauma centers and $99(2.8 \%)$ were treated at the VAMC (-Table 1). Race/ethnicity, socioeconomic status, and insurance status were not reported. Annual incidence was calculated per year ( - Fig. 1). Years were defined as July 1 through June 30 . There was a steady increase in ocular trauma cases from year 1 to year 3 followed by a decline from year 3 to year 6 and a relatively stable period from year 6 to year 8 (-Fig. 1). This was followed by a steady increase in cases from year 8 to year 10 . The total number of cases did not

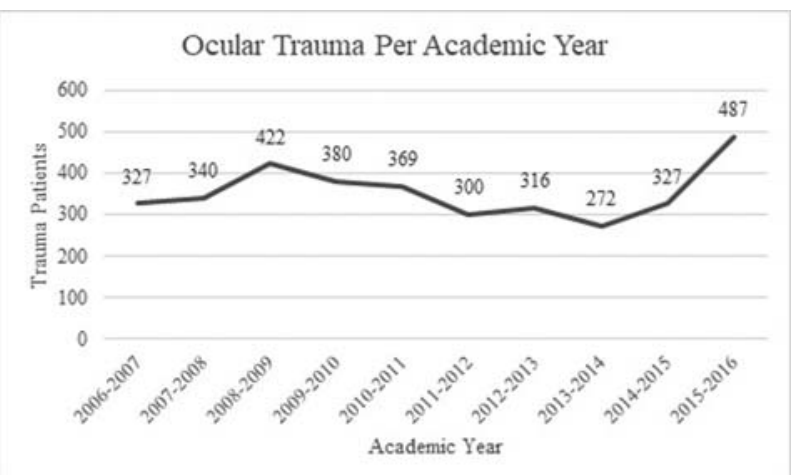

Fig. 1 Total number of ocular trauma consults per academic year. 


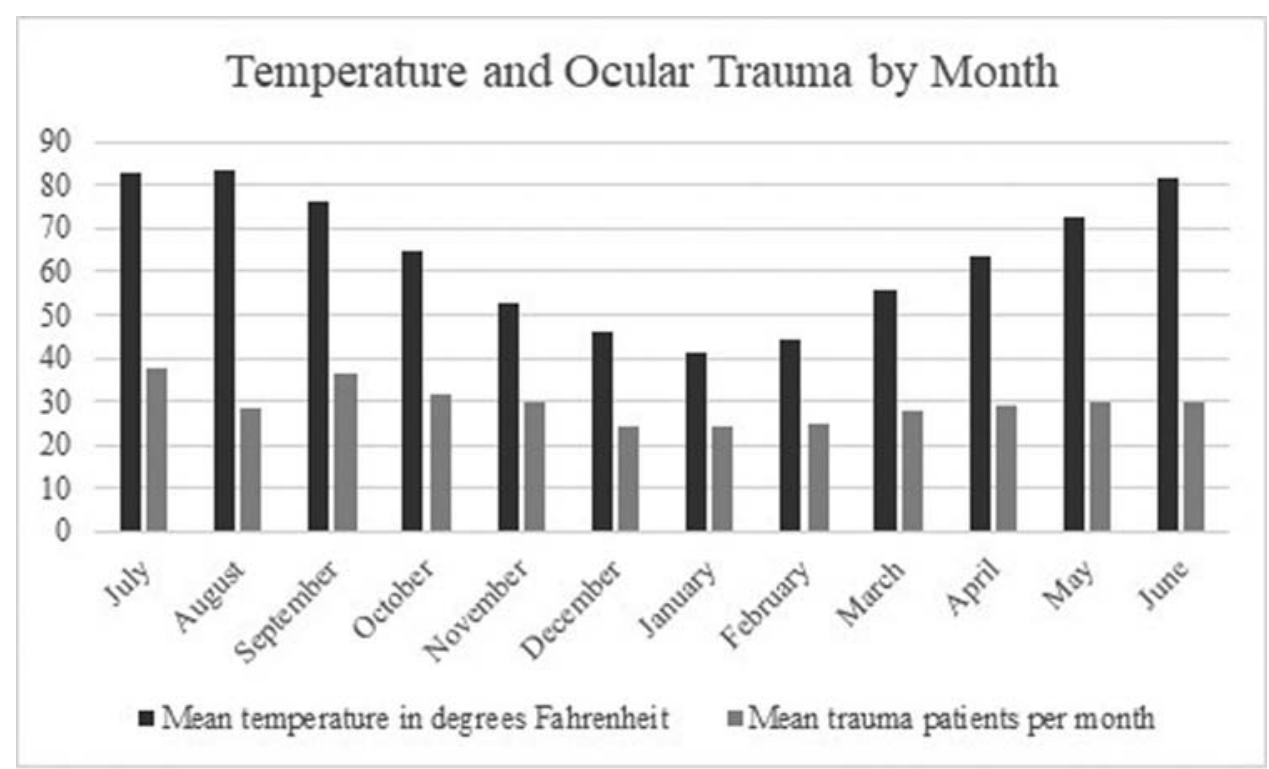

Fig. 2 Mean temperature in Fahrenheit and cases of ocular trauma per month (2006-2016) in Memphis, TN.

display seasonality $(p=0.14)$, as has been previously reported (spring/summer vs. fall/winter) by Ramirez et al. ${ }^{6}$ However, trauma cases did display seasonality $(p=0.0014)$ when comparing summer/fall with winter/spring. When broken down by injury type, all types of injuries were more likely to occur in summer/fall than winter/spring with the exception of retrobulbar hemorrhage, shaken baby, and globe avulsion ( $p=0.035)$. Average monthly temperature data was obtained for 2006 to 2017 (-Fig. 2). August was found to have the highest mean monthly temperature at $83.4^{\circ} \mathrm{F}$, while January had the lowest mean monthly temperature at $41.1^{\circ} \mathrm{F}$ (-Fig. 2). The mean temperature for season was calculated: summer and fall were found to have the highest mean temperature at 82.8 and $64.6^{\circ} \mathrm{F}$, respectively, followed by spring and winter at 63.8 and $46.3^{\circ}$ F. Trauma did show a statistically significant decline in the winter months $(p=0.0069)$. There was peak incidence of trauma cases in July and September at 37.4 and 36.6, respectively (-Fig. 2). The most common diagnoses were orbital fracture (36.6\%), eyelid laceration (20.2\%), and nonpenetrating corneal/conjunctival injury (13.6\%) (-Table 2 ).

\section{Discussion}

Seasonal associations of ocular trauma has been previously reported from nationally reported ED data which showed that cases of ocular trauma are more likely to occur in the spring/summer months compared to fall/winter months. 5,6 Additionally, Stonko et al identified an increased incidence of trauma from April to October with the highest incidence of trauma coinciding with higher temperatures. ${ }^{8}$ While it was previously speculated that temperatures have had an effect for this increased incidence of ocular trauma in spring/summer months, there were no studies comparing the incidence of ocular trauma with temperature. ${ }^{6}$ Our study is unique in that it shows that cases of ocular trauma are more likely to occur in the summer/fall months than the winter/spring months
( $p=0.0014$ ), corresponding to average temperature data from 2006 to 2016 for Memphis, TN that showed a higher mean seasonal temperature for summer/fall $\left(82.8\right.$ and $64.6^{\circ} \mathrm{F}$, respectively) than spring/winter ( 63.8 and $46.3^{\circ} \mathrm{F}$, respectively) (-Fig. 2). ${ }^{11}$ This corresponds with average normal climate data for summer and fall of other major regional cities: Jackson, MS (80.8 and $65^{\circ} \mathrm{F}$, respectively), New Orleans (82.3 and $70.7^{\circ} \mathrm{F}$, respectively), Atlanta (79.3 and $63.5^{\circ} \mathrm{F}$, respectively), Birmingham ( 80.7 and $66^{\circ} \mathrm{F}$, respectively), Jacksonville ( 81.3 and $69^{\circ} \mathrm{F}$, respectively), and Charlotte (77 and $60.5^{\circ} \mathrm{F}$, respectively). ${ }^{11}$ While it was not reported if our patients were victims of crimes, it was hypothesized that increased temperature correlates with aggressive behavior, and there has been an increased rate of violent crimes in years with higher mean temperature. ${ }^{10}$ Increased temperature and hours of daylight correlate with increased crime rate, and aggravated and simple assault are more likely to occur in summer and spring, respectively. ${ }^{9}$ Further study can be taken to compare incidence of ocular trauma and crime rate. In their study of all MVA trauma in Poland from 2004 to 2007, Pawłowski et al identified that July to October had the highest incidence of accidents. ${ }^{12}$ Stonko et al showed that most cases of trauma were victims of MVA(32.9\%); however, this was a less likely cause of ocular injury per data reported by Owens and Mutter (3.3\%).,

Each July, residency training programs experience an influx of new physicians. Previous studies have shown conflicting information about the "July Effect;" however, Shah et al showed an increased incidence of reported medical errors by pediatric residents in July, August, and September compared with May and June. ${ }^{13,14}$ Garber et al showed that medication-related errors committed by internal medicine residents were more common in July and August (adjusted odds ratio: 1.05 ) with a decrease of $16 \%$ over the rest of the academic year. ${ }^{15}$ Finn et al described a $15 \%$ relative reduction in medical error rate, $9.1 \%$ relative reduction in adverse events, and a $7.4 \%$ relative reduction in near misses with increased supervision of medical residents. ${ }^{16}$ Incidence of ocular trauma 
Table 2 Diagnosis by category and season

\begin{tabular}{|c|c|c|c|c|c|}
\hline Diagnosis category & Spring & Summer & Fall & Winter & Total \\
\hline Shaken baby & 14 & 10 & 10 & 11 & 45 \\
\hline Retrobulbar hemorrhage & 8 & 9 & 8 & 9 & 34 \\
\hline Orbital fracture & 383 & 344 & 438 & 326 & 1,491 \\
\hline Eyelid laceration & 210 & 189 & 242 & 182 & 823 \\
\hline Iris/ciliary body injury & 131 & 151 & 127 & 95 & 504 \\
\hline \multicolumn{6}{|l|}{ Traumatic iritis } \\
\hline \multicolumn{6}{|l|}{ Traumatic mydriasis } \\
\hline \multicolumn{6}{|l|}{ Iridodialysis } \\
\hline \multicolumn{6}{|l|}{ Cyclodialysis } \\
\hline \multicolumn{6}{|l|}{ Hyphema } \\
\hline Penetrating globe trauma & 83 & 92 & 97 & 79 & 351 \\
\hline \multicolumn{6}{|l|}{ Corneal laceration } \\
\hline \multicolumn{6}{|l|}{ Scleral laceration } \\
\hline \multicolumn{6}{|l|}{ Ruptured globe } \\
\hline \multicolumn{6}{|l|}{ Intraocular foreign body } \\
\hline Ocular contusion & 54 & 47 & 46 & 32 & 179 \\
\hline Cornea/conjunctival injury & 132 & 164 & 148 & 110 & 554 \\
\hline \multicolumn{6}{|l|}{ Corneal abrasion } \\
\hline \multicolumn{6}{|l|}{ Conjunctival abrasion } \\
\hline \multicolumn{6}{|l|}{ Corneal foreign body } \\
\hline \multicolumn{6}{|l|}{ Conjunctival foreign body } \\
\hline \multicolumn{6}{|c|}{ Non penetrating corneal laceration } \\
\hline \multicolumn{6}{|c|}{ Non penetrating conjunctival laceration } \\
\hline Posterior segment & 11 & 15 & 16 & 11 & 53 \\
\hline \multicolumn{6}{|l|}{ Retinal detachment } \\
\hline \multicolumn{6}{|l|}{ Vitreous hemorrhage } \\
\hline \multicolumn{6}{|l|}{ Choroidal rupture } \\
\hline Lens injury & 4 & 8 & 7 & 2 & 21 \\
\hline \multicolumn{6}{|l|}{ Dislocation } \\
\hline \multicolumn{6}{|l|}{ Traumatic cataract } \\
\hline Intracranial & 2 & 4 & 5 & 3 & 14 \\
\hline \multicolumn{6}{|l|}{ Cranial nerve palsy } \\
\hline \multicolumn{6}{|c|}{ Carotid cavernous sinus fistula } \\
\hline Globe avulsion & 2 & 2 & 0 & 2 & 6 \\
\hline
\end{tabular}

peaks in July (37.4 injuries) which coincides with the beginning of the academic year. This matters most across academic centers in the United States where new residents start on July 1. Ophthalmology is a unique specialty as there is little formal training prior to starting residency. With limited knowledge and diagnostic capabilities, postgraduate year 2 residents are expected to identify ocular pathology, triage patients, and develop a treatment plan, with modest supervision. A recent cross-sectional survey given to program directors and first-year residents in 2016 and 2017 evaluated first year call structure and preparation. Of those who responded, $97.4 \%$ of the residents reported a buddy call system, with $60.8 \%$ having a buddy call system between 3 and 8 weeks. The majority of residents reported taking independent primary call between 4 and 8 weeks (71.9\%). ${ }^{17}$ Call structure for junior residents may include buddy call (a senior resident must see every patient with the junior), must call (where every case must be discussed with a senior resident), back-up call (senior only discusses or comes in for select cases), and independent call. For example, our program utilizes a buddy call system for the first 8 weeks of the academic year followed by a combination of must call and back-up call. However, it is important to note that there is currently no standardized process in place for accredited ophthalmology residencies. Increased supervision 
by senior residents and staff physicians early in the academic year and the new trend for integrated internships for ophthalmology residency programs can help prevent errors and adverse events in the management of ocular trauma as ocular injury leads to legal blindness (visual acuity $<20 / 200$ ) in $27 \%$ of cases and can be present with a normal visual acuity in a white and quiet eye. ${ }^{18}$

Our reported cases were for a single residency program covering consultation for all major hospitals in the metropolitan area of Memphis. Annual incidence of trauma decreased from 2006 to 2014 corresponding with national data that showed a decrease in the incidence of ocular trauma from 2006 to 2013 (-Fig. 1). ${ }^{1,6}$ It was hypothesized that prevention efforts such as the World Health Organization's Program for Prevention of Blindness are responsible for this nationwide trend. ${ }^{2}$ Annual incidence of ocular trauma cases increased from 2014 to 2016 for our dataset. Over this time period, there was no increase in hospital coverage, so it is unclear the reason for increased incidence.

Our patients were predominantly male (64.7\%) with a mean age of 34.9 years. This supports data reported by previous studies that have shown most victims of trauma, including ocular trauma to be predominately younger males. ${ }^{1,5,7,8,19}$ In their study of 11,768 eye emergencies in a Romanian eye emergency room in 2016, Samoilă et al identified that 5,687 patients with ocular injuries related to trauma were predominately male (88\%) with a mean age of 35 years. $^{7}$ Channa et al identified 4,327,336 eye injuries using the Nationwide Emergency Department Sample (NEDS) from 2006 to 2011 of which 66.1\% were male with a mean age of 32 years. ${ }^{1}$ Stonko et al identified 10,684 trauma cases using the Trauma Registry of the American College of Surgeons from 2013 to 2016 of which 74\% were male with a mean age of 45.9 years. ${ }^{8}$ Risk factors for ocular trauma also include race (nonwhite), lower socioeconomic status, and lack of health insurance. ${ }^{2,3,6,18}$ of all trauma types, postinjury visual improvement was shown in $~ 60 \%$ of cases where risk factors listed earlier were not present. ${ }^{18}$ Although the risk factors listed earlier were not recorded for our patients, due to the predominance of young male victims, it is possible that their postinjury visual improvement was limited.

The most common diagnoses in our dataset were orbital fracture (36.6\%), eyelid laceration (20.2\%), and nonpenetrating corneal/conjunctival injury (13.6\%) (-Table 2). Nationwide the most common ocular diagnoses reported from 2006 to 2011 were corneal abrasion (37.7\%), ocular foreign body (29.8\%), direct/indirect trauma to orbit (18.4\%), eyelid laceration (6.3\%), and orbital fracture (3.6\%). ${ }^{1}$ The most common diagnoses reported by Samoilă et al were conjunctivitis and corneal foreign body which made up roughly half of nearly 12,000 patients. ${ }^{7}$ When adjusted for ocular injury, the most common diagnosis reported by Samoilă et al was corneal foreign body (49.7\%), while their reported incidence of orbital fracture and eyelid laceration were only 0.07 and $0.19 \%$, respectively. ${ }^{7}$ While we do not know the exact reason for the discrepancy between our patients, the data from the NEDS, and the data from the Cluj eye ED, our consultation services were not on site at various hospitals and attempted to redirect nonemergent diagnoses such as conjunctivitis to our eye clinics during normal business hours. Additionally, $79 \%$ of our patients were seen at level 1 regional trauma centers which might explain our higher incidence of orbital fractures and eyelid lacerations.

The major weakness of our study is the single region population and the lack of data regarding consults that were redirected to our eye clinics based on phone triage compared with other studies that utilized the NEDS, a stratified sample of administrative billing records from $\sim 1,000 \mathrm{EDs}$ across the United States where diagnoses might not have been confirmed by an ophthalmologist. ${ }^{6}$ In a 2008 study by Statham et al, it was found that general practitioners, emergency room physicians, and optometrist made accurate ocular diagnosis $25.9,4.9$, and $48.2 \%$ of the time, respectively. ${ }^{20}$ The major strength of our study was that patients were evaluated in an acute setting in hospital emergency rooms, and that diagnoses were reported by junior ophthalmology residents, with further confirmation by either senior residents or attending physicians.

\section{Conclusion}

It is important for facial trauma victims with questionable ocular involvement to undergo formal ophthalmologic examination as ocular injury can be present with a preserved visual acuity and normal appearing eye. ${ }^{18}$ Ocular trauma does exhibit an annual and temperature cycle, peaking in hotter months (summer and fall). Our study is unique in that it shows that the highest incidence of trauma is in July (37.4 injuries). This matters most across academic centers in the United States where new residents with limited ophthalmologic training and rudimentary ocular examination skills start on July 1. In residency programs without integrated internships and dedicated ophthalmology rotations, special attention should be taken at the beginning of the academic year to prepare new residents for the proper management of ocular trauma to prevent blindness.

\section{Note}

Meeting presentation at the American Society of Ophthalmic Plastic and Reconstructive Surgery 49th Annual 2018 Fall Scientific Symposium.

\section{Funding}

None.

\section{Conflict of Interest}

J.C.F. reports personal fees from AOTrauma and Horizon Pharmaceuticals, outside the submitted work. All the other authors report no conflict of interest.

\section{References}

1 Channa R, Zafar SN, Canner JK, Haring RS, Schneider EB, Friedman DS. Epidemiology of eye-related emergency department visits. JAMA Ophthalmol 2016;134(03):312-319 
2 Négrel AD, Thylefors B. The global impact of eye injuries. Ophthalmic Epidemiol 1998;5(03):143-169

3 Thylefors B. Epidemiological patterns of ocular trauma. Aust N Z J Ophthalmol 1992;20(02):95-98

4 Owens PL, Mutter R. Emergency Department Visits Related to Eye Injuries, 2008: Statistical Brief \#112. 2011 May. In: Healthcare Cost and Utilization Project (HCUP) Statistical Briefs [Internet]. Rockville (MD): Agency for Healthcare Research and Quality (US); 2006 Feb-2011 May

5 Schliesser JA, Lyon D, Reddy A, et al. Epidemiology of pediatric ophthalmic trauma. J AAPOS 2015;19(04):60. DOI: https://doi. org/10.1016/j.jaapos.2015.07.19

6 Ramirez DA, Porco TC, Lietman TM, Keenan JD. Ocular injury in United States emergency departments: seasonality and annual trends estimated from a nationally representative dataset. Am J Ophthalmol 2018;191:149-155

7 Samoilă O, Ostriceanu S, Samoilă L. Epidemiology of ocular emergencies in Cluj ophthalmology clinic. Rom J Ophthalmol 2016;60(03):165-169

8 Stonko DP, Dennis BM, Callcut RA, et al. Identifying temporal patterns in trauma admissions: informing resource allocation. PLoS One 2018;13(12):e0207766

9 Lauritsen JL, White N. Seasonal Patterns in Criminal Victimization Trends. U.S.: Department of Justice, Office of Justice Programs, Bureau of Justice Statistics; 2014

10 Anderson CA. Temperature and aggression: ubiquitous effects of heat on occurrence of human violence. Psychol Bull106(01):74-96

11 NOAA (National Oceanic and Atmospheric Administration). (July 1st 2006-June 30th 2016). Available at: https://www.ncdc. noaa.gov/cdo-web/. Retrieved June 3, 2018
12 Pawłowski W, Goniewicz K, Schwebel DC, Shen J, Goniewicz M. Road traffic injuries in Poland: magnitude and risk factors. Eur J Trauma Emerg Surg 2019;45(05):815-820

13 Barry WA, Rosenthal GE. Is there a July phenomenon? The effect of July admission on intensive care mortality and length of stay in teaching hospitals. J Gen Intern Med 2003;18(08):639-645

14 Shah AY, Abreo A, Akar-Ghibril N, Cady RF, Shah RK. Is the "July Effect" real? Pediatric trainee reported medical errors and adverse events. Pediatr Qual Saf 2017;2(02):e018

15 Garber A, Nowacki AS, Chaitoff A, et al. Frequency, timing, and types of medication ordering errors made by residents in the electronic medical records era. South Med J 2019;112(01): 25-31

16 Finn KM, Metlay JP, Chang Y, et al. Effect of increased inpatient attending physician supervision on medical errors, patient safety, and resident education: a randomized clinical trial. JAMA Intern Med 2018;178(07):952-959

17 McCoskey M, Shafer B, Akosua N, et al. First-year ophthalmology residency call structure and its association with resident anxiety and confidence. J Acad Ophthalmol 2019;11(01): e9-e15

18 Kuhn F, Morris R, Witherspoon CD, Mann L. Epidemiology of blinding trauma in the United States Eye Injury Registry. Ophthalmic Epidemiol 2006;13(03):209-216

19 Desai P, MacEwen CJ, Baines P, Minassian DC. Incidence of cases of ocular trauma admitted to hospital and incidence of blinding outcome. Br J Ophthalmol 1996;80(07):592-596

20 Statham MO, Sharma A, Pane AR. Misdiagnosis of acute eye diseases by primary health care providers: incidence and implications. Med J Aust 2008;189(07):402-404 